\title{
KENDALI SUHU AIR DENGAN SENSOR TERMOKOPEL TIPE-K PADA SIMULATOR SISTEM PENGISIAN BOTOL OTOMATIS
}

\author{
Dewi Permata Sari ${ }^{1}$, Evelina' ${ }^{2}$, Sabilal Rasyad ${ }^{3}$, Amperawan ${ }^{4}$, Selamat Muslimin ${ }^{5}$ \\ 1,2,3,4,5Program Studi Teknik Elektronika, Politeknik Negeri Sriwijaya \\ e-mail: depeesbaker@gmail.com
}

\begin{abstract}
Abstrak - Pada penelitian ini dibahas mengenai kendali suhu air dengan sensor termokopel tipe$\mathrm{K}$ pada simulator system pengisian botol otomatis. Pengontrolan ini ditujukan untuk menjaga agar botol yang digunakan tidak mengalami pemuaian akibat terisi oleh air dengan suhu tinggi. Dari peneltian didapatkan bahwa botol yang digunakan dalam system ini dapat bertahan atau tidak mengalami pemuaian jika diisi oleh air dengan suhu $\pm 65^{\circ} \mathrm{C}$. Suhu inilah yang kemudian dijadikan sebagai referensi dalam kendali suhu air oleh sensor termokopel. Kendali suhu ini dilakukan dengan cara memantau aktivitas heater agar tidak memanaskan air melebihi suhu setpoint yang ditentukan yaitu $60^{\circ} \mathrm{C}$. Pada proses kendalinya, sensor termokopel dibantu oleh PLC Schneider Modicon TM221M16R. Proses komunikasi antara sensor termokopel dan PLC memanfaatkan analog input yang tersedia diperangkat PLC. Adapun yang dibaca oleh PLC adalah tegangan yang dihasilkan oleh termokopel akibat perbedaan suhu antara hot junction dan cold junction. Tegangan yang dihasilkan oleh perbedaan kedua titik ini sangat kecil, berkisar antara $40 \mu \mathrm{V} /{ }^{\circ} \mathrm{C}$. Oleh karena itu digunakanlah IC op amp LM 358 sebagai penguat tegangan. Keluaran dari LM 358 inilah yang dijadikan sebagai input analog PLC untuk mengontrol suhu air.
\end{abstract}

\section{Kata Kunci : Kendali, LM358, PLC, Suhu, Termokpel}

\begin{abstract}
This observation discusses about water temperature control by using thermocouple Ktype sensor in an automatic bottle filling system simulator. This control system is purposed to keep the bottle unexpand in the effect of high temperature water. In this observation, we obtained that the bottle will defend or unexpand if it is filled with water in a temperature of $\pm 65^{\circ} \mathrm{c}$. This temperature will be used as reference in a water temperature control by using thermocouple sensor. The control system works by monitoring the heater activites in order not to heat the water more than the deterimined setpoint temperature, which is $60^{\circ} \mathrm{c}$. In the control process, a thermocouple sensor is supported by PLC Schneider Modicon TM221M16R. The communication process between the thermocouple sensor and PLC utilizes analog input in PLC device. Generated voltage by a thermocouple in the effect of temperature difference between hot junction and cold junction is read by PLC. Generated voltage in the effect of these two points difference is very small, about $40 \mu \mathrm{V} /{ }^{\circ}$ c. Therefore, IC op amp LM 358 is used as a voltage amplifier. The output of LM 358 is used as PLC analog input to control the water temperature.
\end{abstract}

Keywords : LM358, PLC, Thermocouple K

\section{PENDAHULUAN}

Seiring dengan berkembangnya dunia teknologi maka hal ini mengakibatkan perkembangan juga terjadi pada sector industri, sebabteknologi adalah hal terpenting dalam sebuah industri(Tjiptono, 2014). Semakin hebat teknologi yang digunakan pada sebuah industry maka semakin maju industry tersebut. Dewasa ini berbagai inovasi mulai hadir dalam dunia industri, salah satunya adalah teknologi automasi yang hadir sebagai solusi untuk 
mempermudah pengerjaan dan memberikan hasil yang baikterhadap produk yang dihasilkan (Bashori, Sumardi, \& Setiawan, 2013).

Salah satu aspek pendukung dari system automasi yang penting adalah penggunaan sensor sebagai input yang dipergunakan sebagaipemantik dari kerja output yang digunakan. Sensor suhu merupakan salah satu dari sekianbanyak sensor yang sering kita jumpai dalam dunia industri. Sensor ini berfungsi sebagai pengukur temperature pada material yang diinginkan dan sensor suhu yang sering ditemui pada dunia industry salah satunya adalah sensor termokopel.

\section{TINJAUAN PUSTAKA}

Termokopel merupakan sensor suhu yang mengubah perbedaan suhu menjadi perubahan tegangan, hal ini disebabkan oleh perbedaan kerapatan yang dimiliki oleh masingmasing logam yang bergantung pada massa jenis logam (Wendri, Supardi, Suarbawa, \& Yuliantini, 2012).Sama halnya dengan sensor pada umumnya yang dapat digunakan sebagai input pada sebuah system kendali, sensor termokopel selain dapat membaca perubahan suhu juga dapat berperan sebagai input analog pada sebuah system kendali. Di dalam dunia industri, penggunaan sensor termokopel sering dijumpai pada sistem yang mengharuskan suhu tertentu mengaktifkan output atau dengan kata lain pada saat parameter suhu dijadikan sebagai input analog.

Penelitian terkait sensor termokopel yang berperan sebagai pengendali suhu ini pernah dilakukan oleh (Marto, Risto, Sunarso, \& Pahlanop, 2018) menggunakan board NS.One/32 yang merupakan varian dari board Arduino dan oleh (Huda, 2011) menggunakan mikrokontroler ATMEGA 16. Berdasarkan hal tersebut, maka penulis akan meneliti peranan sensor termokopel sebagai kendali suhu pada system pengisian botol otomatis menggunakan PLC. Dimana pada percobaan ini penulis akan membuat setpoint suhu yang tidak boleh dicapai oleh air dengan cara mengontrol heater yang digunakan untuk memanaskan air.

\section{METODE}

Penelitian ini membahas tentang kendali suhu air pada simulator system pengisian botol otomatis yang diperankan oleh sensor termokopel tipe-K. Tujuan pengendalian suhu ini untuk menjaga agar kondisi suhu air yang ada di dalam tabung reactor tidak melebihi $100{ }^{\circ} \mathrm{C}$. Sebab, apabila suhu melebihi angka $100{ }^{\circ} \mathrm{C}$ akan mengakibatkan pemuaian pada botol yang digunakan. Pengendalian ini dilakukan dengan cara mengontrol kondisi on dan off dari heater.. 


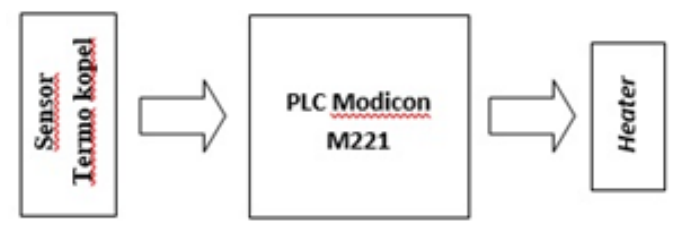

Gambar 1. Blok Diagram Kendali Suhu Oleh Sensor Termokopel

Dalam pelaksanaannya, pengendalian suhu oleh sensor termokopel dibantu oleh PLC Schneider Modicon TM221M16R sebagai pengendali sistem. PLC Schneider Modicon TM221ME16R merupakan salah satu jenis PLC compact yang memiliki fasilitas berupa 8 slot input, 8 slot output, dan 2 slot analog input (Schneider Electric Industries, 2014)

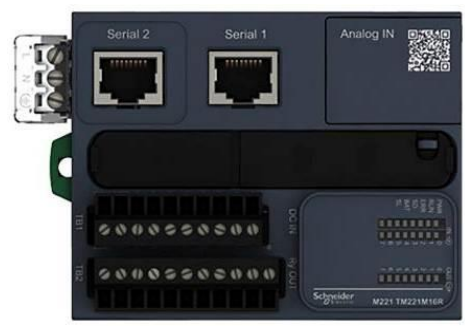

Gambar 2. PLC Schneider Modicon TM221M16R

Pengendalian suhu air ini memanfaatkan slot analog input yang dimilki oleh PLC Schneider Modicon TM221M16R. Hal ini karena sensor termokopel pada prinsipnyamenghasilkan perbedaan tegangan pada setiap kondisi suhu yang berbeda Tegangan yang dihasilkan oleh termokopel relatif kecil sekitar1-70 $\mu \mathrm{V} /{ }^{\circ} \mathrm{C}($ Pertiwi, 2013), sehingga membutuhkan IC omp-amp LM358. IC ini merupakan penguat tegangan non-inverter, atau dengan kata lain muatan input dan ouputnya sama. LM 358 memiliki kemampuan penguatan sebesar.

$$
\operatorname{Gain}(G)=1+\frac{R 2}{R 1}
$$

Penentuan nilai resistor R1 dan R2 yang digunakan sangat berpengaruh terhadapkemampuan penguatan yang dilakukan oleh LM385 


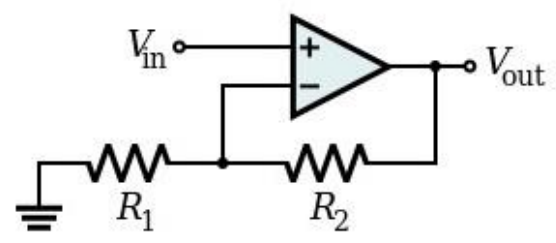

Gambar 3. Rangkaian Op-Amp Non-Inverting amplifier

Adapun pembacaan analog input oleh PLC berupa tegangan dari sensor termokopel diperoleh dari output IC LM385 yang berada pada pin 1 dan 4.

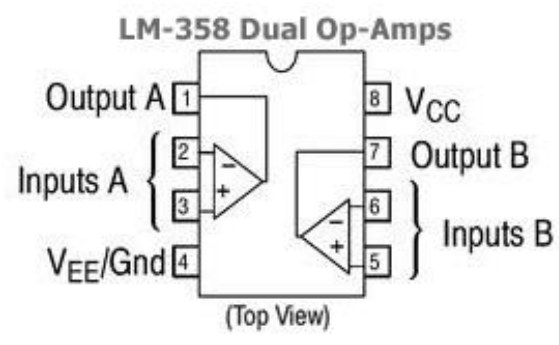

Gambar 4. Rangkaian Op-Amp Non-Inverting amplifier

\section{HASIL DAN PEMBAHASAN}

Dalam penelitian pengendalian suhu air ini, didukung dengan sebuah simulator system pengisian botol yang terdiri dari sebuah konveyor, sebuah sensor proximity dan dua buah tabung. Satu tabung berfungsi sebagai sumber air, satu tabung berfungsi sebagai reaktor yang di dalamnya terdapat sensor upper, sensor lower, sensor termokopel dan heater

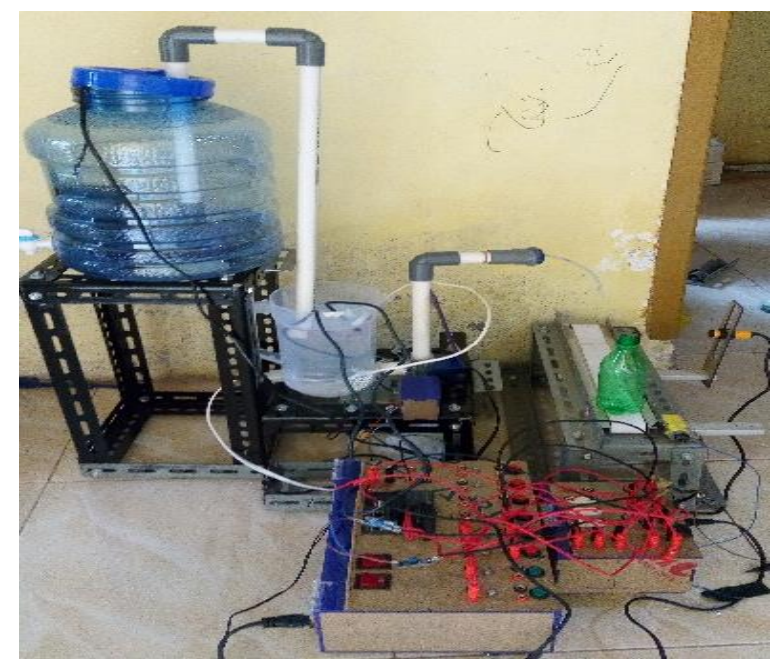




\section{Gambar 5. Simulator Sistem Pengisian Botol Otomatis}

PLC yang digunakan dalam penelitian ini dikemas menjadi sebuah modul yang disertai dengan junction box sebagai penghubung antara input dan output PLC dengan input dan output system pengisian botol otomatis.

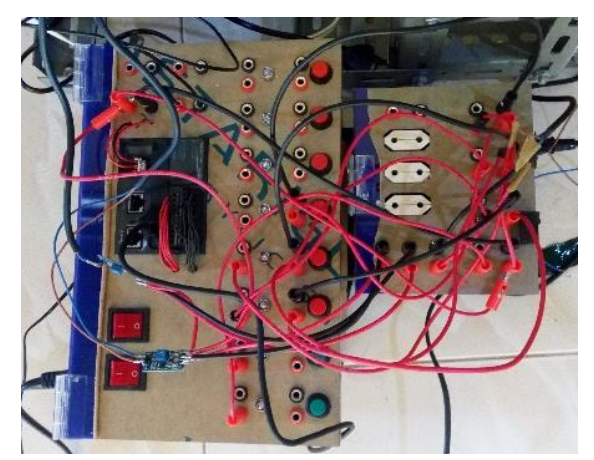

Gambar 6. Modul PLC dan Junction Box

Pengendalian suhu air pada system pengisian botol otmatis ini ditujukan untuk menjaga agar kondisi botol tidak memuai akibat terisi oleh air dengan suhu yang tinggi. Kendali suhu yang diperankan oleh sensor termokopel ini dirancang pada sebuah simulator tabung reaktor yang ditempatkan pada sisi atas tabung dengan tujuan agar sensor termokopel-mendeteksi suhu air yang terendah dalam proses kendalinya.

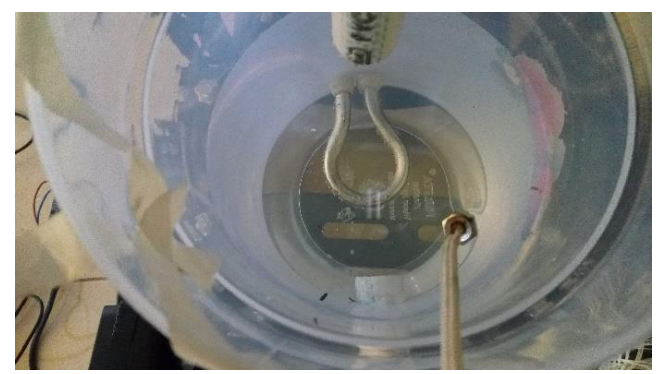

Gambar 7. Penempatan Sensor Termokopel

Berdasarkan hasil penelitian, botol yang digunakan pada system ini akan mengalami pemuaian apabila terisi air dengan suhu lebih dari $65^{\circ} \mathrm{C}$.

Tabel 1. Nilai suhu air terhadap kondisi botol

\begin{tabular}{|c|c|}
\hline Suhu( $\left({ }^{\circ} \mathrm{C}\right)$ & Memuai \\
\hline 100 & Ya \\
\hline 95 & Ya \\
\hline 80 & Ya \\
\hline 75 & Ya \\
\hline
\end{tabular}




\begin{tabular}{|c|c|}
\hline $\mathbf{7 0}$ & Ya \\
\hline $\mathbf{6 5}$ & Tidak \\
\hline 60 & Tidak \\
\hline
\end{tabular}

Berdasarkan table diatas, maka peneliti menetapkan setpoint kendali heater pada suhu $60^{\circ} \mathrm{C}$ yang terukur oleh sensor termokopel dengan toleransi suhu tertinggi sekitar $\pm 65^{\circ} \mathrm{C}$.

Tabel 2. Nilai suhu air terhadap tegangan sensor termokopel

\begin{tabular}{|c|c|}
\hline Suhu ('C) & Tegangan (V) \\
\hline $\mathbf{6 0}$ & 0,444 \\
\hline $\mathbf{5 9}$ & 0,441 \\
\hline $\mathbf{5 6}$ & 0,432 \\
\hline $\mathbf{5 5}$ & 0,429 \\
\hline $\mathbf{5 1}$ & 0,416 \\
\hline $\mathbf{5 0}$ & 0,413 \\
\hline $\mathbf{4 6}$ & 0,400 \\
\hline $\mathbf{4 5}$ & 0,397 \\
\hline $\mathbf{4 1}$ & 0,384 \\
\hline $\mathbf{4 0}$ & 0,381 \\
\hline $\mathbf{3 6}$ & 0,368 \\
\hline $\mathbf{3 5}$ & 0,365 \\
\hline $\mathbf{3 1}$ & 0,352 \\
\hline
\end{tabular}

Pengukuran yang tertera pada table diatas merupakan pengukuran tegangan yang dihasilkan oleh sensor termokopel setelah dilakukan penguatan oleh sensor LM358. Nilai suhu yang tertera pada tabe ldiatas diperoleh dari pembacaan modul yang sudah terpasang pada sensor termokopel. Adapun Pengukuran tegangan pada LM358 dilkakukan dengan cara meletakkan alat ukur pada pin 1 (output) dan 4 (ground) dari LM358. Dari tegangan yang telah diukur tersebut akan dibaca oleh PLC sehingga dapat mengendalikan suhu air dengan cara mengontrol aktivita sheater yang telah ditentukan setpoint nya yaitu sebesar $60^{\circ} \mathrm{C}$.

Tabel 3. Nilai suhu air terhadap aktivitas heater

\begin{tabular}{|c|c|}
\hline Suhu ( ${ }^{\circ}$ C) & Aktivitasheater \\
\hline 31 & On \\
\hline 35 & On \\
\hline 36 & On \\
\hline 40 & On \\
\hline 41 & On \\
\hline 45 & On \\
\hline 46 & On \\
\hline $\mathbf{5 0}$ & On \\
\hline $\mathbf{5 1}$ & On \\
\hline $\mathbf{5 5}$ & On \\
\hline $\mathbf{5 6}$ & On \\
\hline $\mathbf{5 9}$ & On \\
\hline $\mathbf{6 0}$ & Off \\
\hline & \\
\hline
\end{tabular}


Dari hasil penelitian yang dituangkan dalam table diatas, diketahui bahwa aktivitas heaterakan berhenti pada saat sensor termokopel mendeteksi suhu terendah di dalam tabung reaktor saat melewati angka $60^{\circ} \mathrm{C}$. Hal ini memungkinkan botol yang digunakan pada system ini tidak mengalami pemuaian pada saat terisi oleh air.

\section{KESIMPULAN}

Kendali suhu air oleh sensor termokopel dalam simulator sistem pengisian botol otomatis ini dapat membantu terhindarnya pemuaian botol yang digunakan akibat terisi dengan air suhu tinggi. Kendali ini dilakukan dengan mengontrol aktivitas heateragar tidak memanaskan air melebihi suhu $60{ }^{\circ} \mathrm{C}$. Kendali ini dilkakukan dengan memanfaatkan tegangan yang dihasilkan oleh sensor termokopel akibat perbedaan suhu yang terjadi antara titik hot junction dan titik cold junction. Pengunaan sensor termokopel ini dapat digunakan pada suhu yang lebih tinggi hingga mencapai $1250{ }^{\circ} \mathrm{C}($ Omega, 2012). Berhubung dalam penelitian ini hanya berupa simulator, maka suhu yang diukur hanya mencapai $60^{\circ} \mathrm{C}$..

\section{DAFTAR PUSTAKA}

[1] Bashori, Z., Sumardi, \& Setiawan, I. (2013). Pengendalian Temperatur pada Plant Sederhana Electric Furnace Berbasis Sensor Thermocouple dengan Metode Kontrol PID. Jurnal Teknik Elektro, 2, 1-8.

[2] Huda, S. N. (2011). Rancang Bangun Sistem Pengendali Temperatur Furnance Dengan Menggunakan Sensor Termokopel Tipe-K Berbasis Mikrokontroler ATMEGA 16. Depok.

[3] Marto, S., Risto, G., Sunarso, A., \& Pahlanop, B. (2018). Rancang Bangun Sistem Pemantau dan Kendali Suhu Pada Model Alat Pirolisis Plastik. Prisma Fisika, VI(1), 4956.

[4] Omega. (2012). Revised Thermocouple Reference Tables.

[5] Pertiwi, P. K. (2013). Termokopel. Surabaya.

[6] Schneider Electric Industries. (2014). Product Data Sheet of TM221M16R

[7] Tjiptono, F. (2014). Pemasaran Jasa. CV. Andi Offset. Yogyakarta. Yogyakarta

[8] Wendri, N., Supardi, I. W., Suarbawa, K. N., \& Yuliantini, N. M. (2012). Alat Pencatat Temperatur Otomatis Menggunakan Termokopel Berbasis Mikrokontroler AT89S51. Buletin Fisika, 13(1), 29-33 